\title{
Contents: Research for All 5 (2)
}

Editorial: Engagement for change

Sophie Duncan and Sandy Oliver

Knowledge exchange and the creative industries: A reflective commentary on current practice

Emma Cole

Future Places Toolkit: Engaging communities through augmented reality and performance

Paul Clarke

Therapeutic creativity and the lived experience of grief in the collaborative fiction film Lost Property

Lesel Dawson, Jimmy Hay and Natasha Rosling

Developing arts-based methods for exploring virtual reality technologies:

A university-industry case study

Stuart Gray, Chris Bevan, Kirsten Cater, Jo Gildersleve, Caroline Garland and

Oliver Langdon

Knowledge exchange in the arts and humanities as creative economy policy assemblage

Simon Moreton

Small grants, big impact: The Institute of Classical Studies' seed funding scheme for public engagement

Emma Bridges

Public engagement with research: Citizens' views on motivations, barriers and support

Marion Dreyer, Hannah Kosow, Anja Bauer, Blagovesta Chonkova,

Ventseslav Kozarev and Lada Timotijevic

SCENE: A novel model for engaging underserved and under-represented audiences in informal science learning activities

Lindsay Keith and Wyn Griffiths

STEM escape rooms for public engagement

Amanda Mathieson and Edward Duca

The dynamics of working at intersections: Reflections from exploring inequalities

Siobhan Morris and Olivia Stevenson

'Bottoms up': A case study on integrating public engagement within a university culture

Aoibhinn Ní Shúilleabháin, Fergus McAuliffe and Éidín Ní Shé

Hidden persuaders on film: Exploring young people's lived experience

through visual essays

Daniel Pick, Mary-Clare Hallsworth and Sarah Marks

This is an open-access journal distributed under the terms of the Creative Commons Attribution Licence (CC-BY) $4.0 \mathrm{https}$ ://creativecommons.org/licenses/by/4.0/, which permits unrestricted use, distribution and reproduction in any medium, provided the original author and source are credited. https://doi.org/10.14324/RFA.05.2.00. (ISSN 2399-8121). https://www.uclpress.co.uk/pages/research-for-all 
Evaluating the short-term and long-term impact of an interactive science show Wendy J. Sadler

Meeting the challenges of public engagement, research impact and research participation as a baby and child lab

Gideon Salter, Tina Altdörfer, Geraldine Brown and Malinda Carpenter

Patient and public involvement and engagement: Practice case study with reflections and learnings from a small rural district general hospital

Zoë A. Sheppard, Sarah Williams, Richard Lawson and Kim Appleby

The Olive Ridley Project (ORP): A successful example of how to engage researchers, conservation practitioners and civil society

Martin Stelfox, Mercedes Martin-Cereceda, Karim Vahed, Jillian Hudgins, Stephanie Köhnk, Usman lqbal, Ibrahim Shameel, Joana M. Hancock and Michael Sweet 